\title{
APPROACH TO A RELIABILITY FRAMEWORK FOR MEMBRANE STRUCTURE DESIGN AND ANALYSIS
}

\author{
L. PYL ${ }^{1}$, X. WANG ${ }^{2}$, E. DE SMEDT ${ }^{3} \&$ M. MOLLAERT ${ }^{4}$ \\ ${ }^{1}$ Prof. Dr IR, Vrije Universiteit Brussel (VUB), Department of Mechanics of Materials and \\ Constructions, Belgium. \\ ${ }^{2} \mathrm{MSc}$ - student in Architectural Engineering, Vrije Universiteit Brussel (VUB), Belgium. \\ ${ }^{3} \mathrm{PhD}$ - Researcher, Vrije Universiteit Brussel (VUB), Department of Architectural Engineering, Belgium. \\ ${ }^{4}$ Prof. Dr IR, Vrije Universiteit Brussel (VUB), Department of Architectural Engineering, Belgium.
}

\begin{abstract}
Research into structural reliability for tensile structures is needed. The semi-probabilistic format for verification of so-called form-passive structures is well-established in the Eurocodes. Partial factors are the main features of this semi-probabilistic or design value method. Whereas for conventional structures these partial factors are calibrated to previous experience [1], appropriate partial factors have to be proposed and evaluated for tensile structures. A cable net structure built in 1958 was used as a case study to gain insight into the effect of partial factors according to Eurocode 3 (steel structures). Prestress contributes to the stiffness in the non-linear structural behaviour of membrane structures and thus increasing the prestress with factor 1.35 according to the Eurocodes might be non-conservative. The article investigates the effect of the partial factor for prestress (1.0 or 1.35) on a membrane structure. A similar geometry as the steel cable net structure is designed and analysed for comparison with the cable net structure. For the primary steel structure the partial factor for prestress 1.35 has to be applied. An in-depth study of the effect of the partial factor for prestress on the stress distribution in the membrane in warp and weft direction is performed. The stress distribution clearly depends on the boundary conditions. A sound conclusion though requires a thorough in-depth study for different shapes and membrane types. In a first step towards a reliability approach, the structural reliability of a three segments cable net structure is currently being analysed, taking into account the uncertainties associated with the pretensioned system.
\end{abstract}

Keywords: cable net structure, Eurocode, partial factors, structural reliability, tensile surface structure.

\section{PROBLEM STATEMENT}

Membrane structures, as lightweight structures, gained growing interest since the 1950s, in particular as they enable the designer to cover large spans. However, only a limited number of engineering offices is competent to design and analyse this type of structures. Contrary to the well-established Eurocodes for conventional buildings, there is still no harmonized European standard specific for membrane structures, even though tensile surface structures were introduced more than 60 years ago. The geometrically non-linear behaviour of membrane structures gives rise to an action effect which is not proportional to the increase of the action. As the superposition principle is no longer valid, this article investigates the effect of the partial factor for prestress (1.0 or 1.35) on a membrane structure. This is a first step in dealing with structural reliability of geometrical non-linear structures within the framework of the structural Eurocodes.

A temporary, steel cable net canopy on the World Exposition of 1958 at the Heysel in Brussels (analysis by André Paduart, then professor at Brussels Free University, Brussels, Belgium) [2] inspired the authors for the present case study. Likewise, a membrane structure was designed and analysed, keeping the original geometry but replacing the (discontinuous) cable net and non-load bearing textile cover by a (continuous) structural membrane cover. Research is done on the effect of the partial factor for prestress of 1.0 and 1.35 for different wind load cases. In particular the effect of the partial factor for prestress 1.0 versus 1.35 
on the stress distribution in the membrane in warp and weft direction is studied. First, the original steel cable net is introduced. Secondly, the effect of a partial factor for prestress of 1.0 or 1.35 for the considered structure is analysed. More specifically, it examines whether the partial factor will generate the 'worst case' loading, knowing that prestress contributes to stiffness. In Ultimate Limit State (ULS) the maximum stress in the membrane surface is checked and the minimum is verified to avoid that tensions become compressions. The stress distribution in warp and weft direction is analysed. In Serviceability Limit State (SLS) the deflection is verified to avoid ponding as well as inversion of curvature.

\section{EFFECT OF THE PARTIAL FACTOR FOR PRESTRESS ON SAFETY AND SERVICEABILITY}

The persistent design situation, referring to the condition of normal use is selected. In order to encompass all conditions that can occur during or after construction (e.g. creep), particular attention needs to be paid to the partial factor for prestress $\gamma_{P}$. Setting the prestress level during or adjusting after construction is not always very precise. That is why in practice, the applied prestress level could be different from the design value. The most unfavorable combination of actions for the design stress levels in ULS can, according to EN 1990 A.2.2.1(12) [3] and to the Prospect for European Guidance for the Structural Design of Tensile Membrane Structures [4], be obtained assuming prestress as an additional action besides the considered external actions. Prestress being a permanent action, the partial factor for prestress $\gamma_{P}=1.0$ and $\gamma_{P}=1.35$ are used. As wind loading on doubly curved structures remains insufficiently defined in Eurocode 1 [5], approximations have to be made.

In SLS, the deflection is verified to avoid ponding as well as inversion of curvature. Decreasing the prestress reduces the stiffness and thus will lead to unfavorable larger deflections. A partial factor for prestress $\gamma_{P} \leq 1.0$ could reflect this. In the present study, the partial factor for prestress $\gamma_{P}=1.0$ is considered in SLS.

\section{CASE STUDY DESCRIPTION}

The geometry, loads and material information in this article are based upon one of the coauthors' MSc-thesis [6] and later publications [2, 7].

Before the structural Eurocodes were established, A. Paduart (1914-1985) analysed the structure designed by architect O. Schlomblood named "the Band Stand". It was an anticlastic cable net structure that sheltered the musicians against weather conditions. The length (denoted as $x$-direction, Fig. 1, left drawing) equals $13.91 \mathrm{~m}$, the width (denoted as $y$-direction, Fig. 1, right drawing) equals $20.4 \mathrm{~m}$ [10]. The cable net goes from the top of the high mast at a height of $7.5 \mathrm{~m}$ to a lower curved concrete wall with a height varying between $2.82 \mathrm{~m}$ and $3.22 \mathrm{~m}$ (denoted as $z$-direction, Fig. 1, left drawing). The cable net consists out of sixteen catenary cables (CC) in the longitudinal or $x$-direction and five tension cables (TC) in the transverse direction or $y$-direction. The top of the highest mast was connected to the ground by a vertical cable (VC). The top of the lateral poles were connected to the ground by two lateral cables (LC). The top of the highest mast is connected with the curved concrete wall with an edge cable (EC).

3.1 Materials and sections considered in the original calculation note

Table 1 gives the data of the steel components calculated by Paduart. 


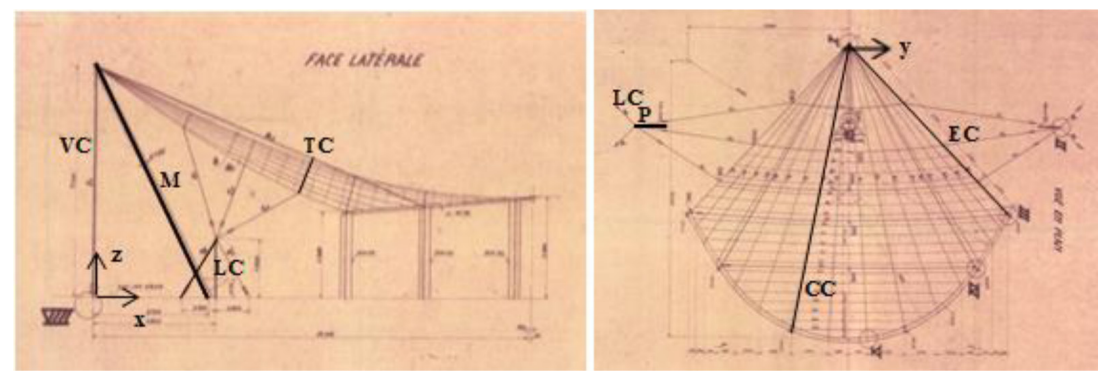

Figure 1: Designation of the different elements and axes: VC vertical cable, LC lateral cable, CC catenary cable, TC tension cable, EC edge cable, M Mast and P Pole (left: elevation, right: plan view) [[10], file 2326].

Table 1: Properties of the components calculated by Paduart.

\begin{tabular}{lll}
\hline & Mast & Pole \\
\hline Buckling length $[\mathrm{m}]$ & 6.08 & 1.9 \\
Outer diameter $[\mathrm{mm}]$ & 159 & 51 \\
Wall thickness [mm] & 6 & 3 \\
Radius of gyration $[\mathrm{mm}]$ & 54.1 & 17 \\
& Catenary cables & Tension cables \\
Rupture load $[\mathrm{kN}]$ & 16.9 & 104.0 \\
\hline
\end{tabular}

3.2 Load models considered in the original calculation and according to the Eurocode

In the calculation note of Paduart (the units are converted to the SI-units), the following load cases are considered:

- Self-weight of the construction: $0.06 \mathrm{kN} / \mathrm{m}^{2}$.

- Wind: $0.50 \mathrm{kN} / \mathrm{m}^{2}$ (upward - in Paduart's calculations wind acts vertically) for the tension cables.

- Accidental loading: $0.10 \mathrm{kN} / \mathrm{m}^{2}$ (downward).

The self-weight has been combined with the distributed loads $0.25 \mathrm{kN} / \mathrm{m}^{2}$ representing the prestress:

- Load on the catenary cables: $0.25 \mathrm{kN} / \mathrm{m}^{2}+0.03 \mathrm{kN} / \mathrm{m}^{2}=0.28 \mathrm{kN} / \mathrm{m}^{2}$.

- Load on the tension cables: $0.25 \mathrm{kN} / \mathrm{m}^{2}-0.03 \mathrm{kN} / \mathrm{m}^{2}=0.22 \mathrm{kN} / \mathrm{m}^{2}$.

The maximum loading per cable direction:

- Load on the catenary cables: $0.28 \mathrm{kN} / \mathrm{m}^{2}+0.05 \mathrm{kN} / \mathrm{m}^{2}$ (accidental) $=0.33 \mathrm{kN} / \mathrm{m}^{2}$.

- Load on the tension cables: $0.22 \mathrm{kN} / \mathrm{m}^{2}+0.25 \mathrm{kN} / \mathrm{m}^{2}$ (wind) $=0.47 \mathrm{kN} / \mathrm{m}^{2}$. 


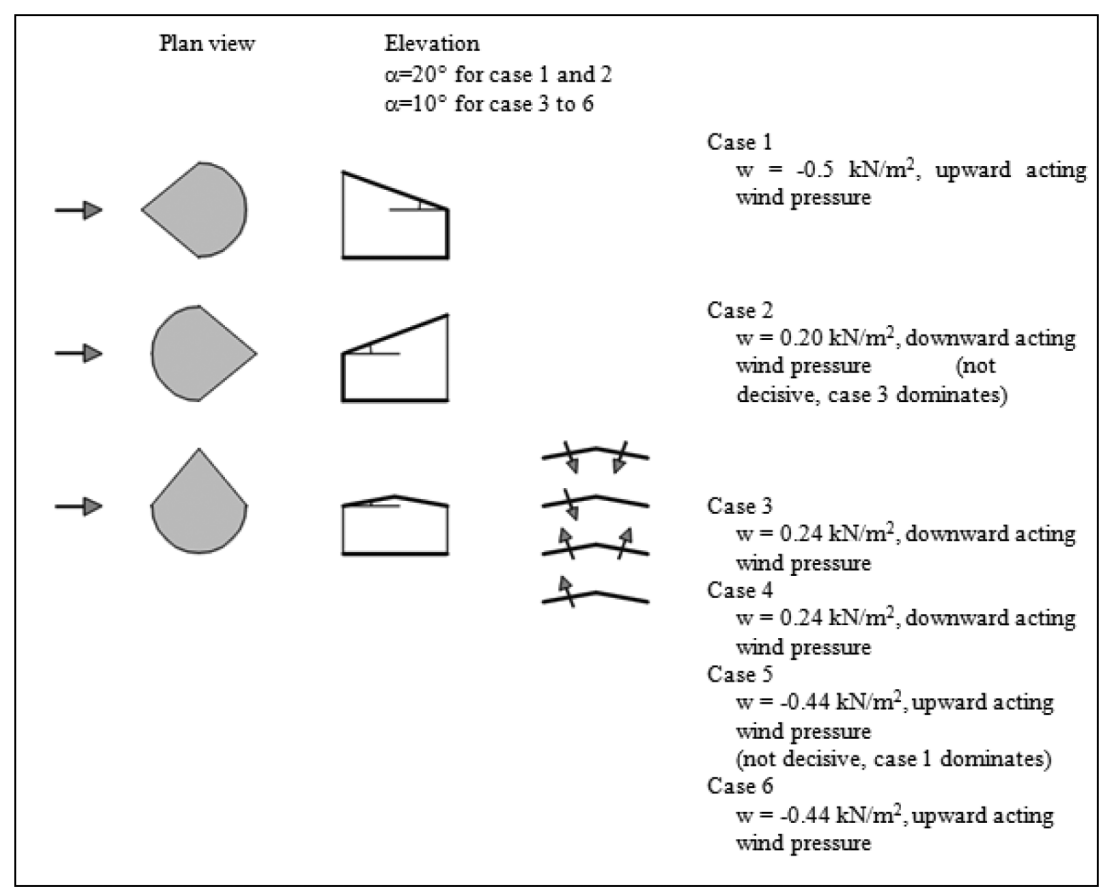

Figure 2: Un-factored wind pressure, to be applied perpendicular to the surface.

The latter four values can be understood as follows: the wind load will partly be taken by the TC (increasing the stress), partly by the CC (reducing the stress). To remain tensioned under load, the prestress is set to a distributed load of $0.25 \mathrm{kN} / \mathrm{m}^{2}$. From this, the prestress per cable segment can be calculated. The cable forces under the maximum loading of $0.33 \mathrm{kN} / \mathrm{m}^{2}$ (CC) and $0.47 \mathrm{kN} / \mathrm{m}^{2}$ (TC) are obtained by applying a factor of $33 / 25$ and $47 / 25$ respectively.

In the analysis according to the Eurocode (performed with the software Easy [8]), the following load cases are considered:

- The prestress, being a design parameter, is chosen according to the prestress foreseen by Paduart.

- For wind loading, six cases are specified according to EN 1991-1-4 [5] Table 7.1, Table 7.3 and Table 7.7 and summarised in Fig. 2: cases 1, 3, 4 and 6 can be decisive. A basic velocity pressure $v_{b}=7.45 \mathrm{~m} / \mathrm{s}$ is assumed. The basic wind pressure is $q_{b}=0.34 \mathrm{kN} / \mathrm{m}^{2}$.

- As the canopy was designed to be dismantled after summer, behaviour under snow load was not checked.

\section{MEMBRANE STRUCTURE ANALYSES}

\subsection{Material characteristics of the membrane}

The membrane prestress is set to $6.0 \mathrm{kN} / \mathrm{m}$ in the longitudinal direction ( $\mathrm{x}$-direction or warp direction) and $6.5 \mathrm{kN} / \mathrm{m}$ in the transverse direction (y-direction or weft direction). This value is set high enough to avoid inversion of curvature under loading. The properties of the mem- 
brane are summarized in Table 2. The chosen grid for the membrane is regular orthogonal as shown in Fig. 3.

The process of finding the appropriate equilibrium shape for the membrane structure was one of trial and error. The basic principle was that the coordinates of the points connecting the membrane to the primary structure stay at the same position and that the shape fits well. In Fig. 3, it can be seen that the anti-clastic curvature of the membrane is not exactly the same as the curvature of the cable net, but that the overall geometry corresponds.

The stress values of the membrane are compared with five points as indicated in Fig. 4. Next, the four dominant variable wind load cases (Cases 1, 3, 4 and 6, see Fig. 2) are retained in the combinations of actions in the ULS check with a partial factor for variable actions $\gamma_{Q}=1.5$. To evaluate the influence of the partial factor for prestress $\gamma_{P}$ on the structural design, this factor is set first to 1.0 , next to 1.35 .

The stress variation in the five points in the membrane without external loading with prestress factor 1.0 and 1.35 is summarized in Table 3 and indicated in Fig. 4. The membrane stress is expressed as the forces in the warp or weft direction per unit width of the membrane in $[\mathrm{kN} / \mathrm{m}]$. These membrane stresses should be compared with the type II PVC-coated polyester fabric strength of $80 \mathrm{kN} / \mathrm{m}$. In practice, a safety coefficient of 4 to 5 is used for the membrane. It will become clear from the results (highlighted in bold in Table 3) that locally, the stresses in the membrane exceed $20 \mathrm{kN} / \mathrm{m}$. More performant fabrics, edge reinforcement or double layers of fabric are thus required in a real application.

The membrane stress distribution in Table 3 without external loading shows a small variation in warp and weft direction. The differences in the central point are negligible and limited in the edge wall and corner points. Only in the mid-wall point a difference of $3 \mathrm{kN} / \mathrm{m}$ can be observed. With the partial factor for prestress $\gamma_{P}=1.35$, the stresses increase in the range $[2.1 ; 3.1] \mathrm{kN} / \mathrm{m}$. The rows in Table 3 highlighted in grey are with a partial factor for prestress $\gamma_{P}=1.0$, the non-highlighted ones are with a partial factor for prestress $\gamma_{P}=1.35$.

Table 2: Properties of the PVC-coated polyester membrane.

\begin{tabular}{ll}
\hline Stiffness warp direction $[\mathrm{kN} / \mathrm{m}]$ & 753.0 \\
Stiffness weft direction $[\mathrm{kN} / \mathrm{m}]$ & 612.0 \\
Crimp $[\mathrm{kN} / \mathrm{m}]$ & 219.5 \\
Shear $[\mathrm{kN} / \mathrm{m}]$ & 30.0 \\
Weight per $\mathrm{m}^{2}\left[\mathrm{kN} / \mathrm{m}^{2}\right]$ & 0.0105 \\
\hline
\end{tabular}

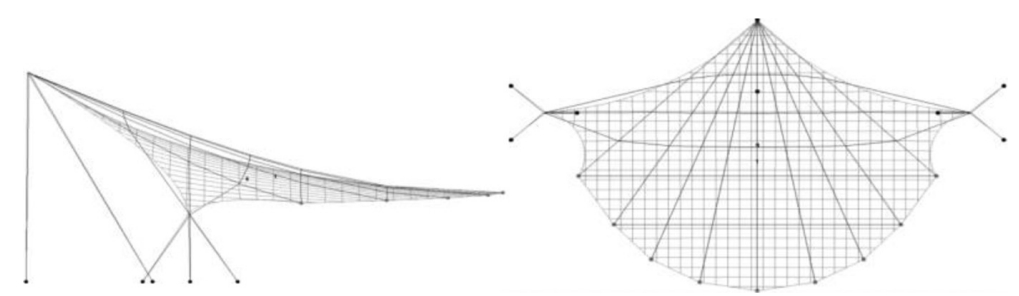

Figure 3: Membrane structure (rectangular mesh) fitting the shape of the cable net structure as good as possible (left: elevation, right: plan view). 


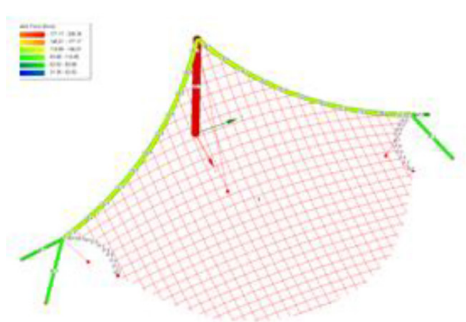

a)

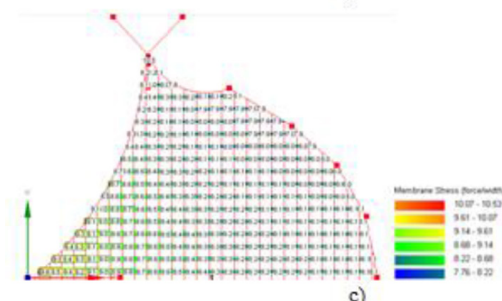

c)

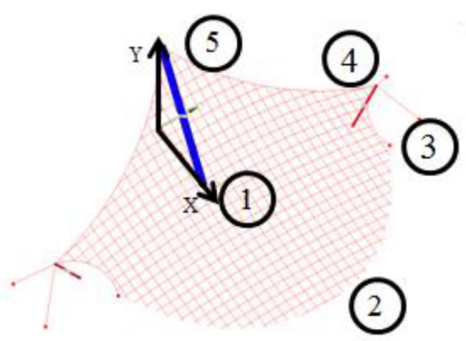

b)

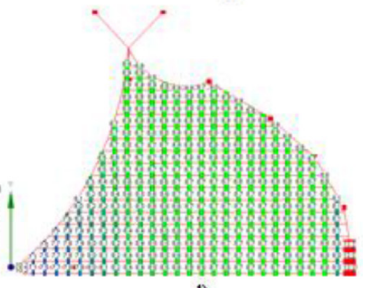

d)

Figure 4: (a) Cable forces, (b) mast and poles forces with indication points that are checked (1 central point; 2 point mid-wall; 3 point edge wall; 4 low corner point; 5 high corner point), (c) membrane stress in warp and (d) weft after form finding (without external loading) - prestress factor 1.35 .

Although the membrane canopy and steel cable net have a similar anticlastic shape and the same wind loading cases are applied, the stress pattern in the membrane is much more complex than the distribution of forces in the cable net [7]. For the canopy under upward acting wind pressure (wind case 1), the membrane stress in the $\mathrm{x}$-direction or longitudinal hanging direction decreases, while in the y-direction or transversal arching direction the membrane stress increases, which is logical since the curvature in the hanging line should decrease and in the arching line should increase under upward acting wind pressure. This is confirmed in membrane stress distribution in the central point in the warp and weft direction. On the other hand, for local zones, an increase in the membrane stress in both directions can be observed. Local stress concentrations occur. There are several possible explanations for this complex stress transfer in the region of the poles, mast and wall: the presence of the fixed boundaries, each of them with their own peculiarities (connected in a point for mast and poles and along a line for the wall), interaction between the fabric in longitudinal and transversal direction and a quite short span of fabric locally. The membrane stresses in wind case 1 and a partial factor for prestress 1.35 dominate the design of the membrane (underlined values in Table 3 ). As can be seen from the results in Table 3, a partial factor for prestress 1.35 generally gives an increase in membrane stress but the increment is not equally important in both directions. This non-linear behaviour is typical of membrane structures.

When the canopy is affected by downward acting wind pressure (wind case 3 ), the membrane stress in the x-direction or longitudinal hanging direction increases, while in the y-direction or transversal arching direction the membrane stress decreases, which is logical since the curvature in hanging line should increase and in arching line should decrease under downward acting wind pressure. On the other hand, for local zones, the effect of forces applied on the membrane will be much more complicated than in the central points, and the interaction between the fabric in longitudinal and transversal direction influences the stress. In general, a more equal stress distribution and lower values can be observed in wind case 3 . 
Table 3: Membrane stress distribution in $[\mathrm{kN} / \mathrm{m}]$ (the forces per unit width of the membrane) without external loading (FF) and for the four design $\left(\gamma_{Q}=1.5\right)$ wind load cases W1, W3, W4 and W6 (the un-factored values are given in Fig. 2).

\begin{tabular}{|c|c|c|c|c|c|c|}
\hline Load combinations & $\begin{array}{l}\text { Warp }(\mathrm{x})- \\
\text { weft }(\mathrm{y}) \\
\text { direction }\end{array}$ & $\begin{array}{l}1 \text { central } \\
\text { point }\end{array}$ & $\begin{array}{l}2 \text { point } \\
\text { mid-wall }\end{array}$ & $\begin{array}{l}3 \text { point } \\
\text { edge wall }\end{array}$ & $\begin{array}{l}4 \text { low } \\
\text { corner } \\
\text { point }\end{array}$ & $\begin{array}{l}5 \text { high } \\
\text { corner } \\
\text { point }\end{array}$ \\
\hline \multirow[t]{2}{*}{ FF-P $\times 1.0$} & $\mathrm{x}$ & 6.2 & 6.0 & 6.0 & 7.8 & 7.1 \\
\hline & $\mathrm{y}$ & 6.3 & 9.1 & 6.6 & 6.6 & 7.6 \\
\hline \multirow[t]{2}{*}{ FF-P $\times 1.35$} & $\mathrm{x}$ & 8.4 & 8.1 & 8.2 & 10.5 & 9.6 \\
\hline & $\mathrm{y}$ & 8.6 & 12.2 & 9.0 & 8.9 & 10.2 \\
\hline \multirow[t]{2}{*}{$\mathrm{W} 1 \times 1.5-\mathrm{P} \times 1.0$} & $\mathrm{x}$ & 0.6 & 0.2 & 4.0 & 21.6 & 2.1 \\
\hline & $\mathrm{y}$ & 20.8 & 8.7 & 26.4 & 11.4 & 96 \\
\hline \multirow[t]{2}{*}{$\mathrm{W} 1 \times 1.5-\mathrm{P} \times 1.35$} & $\mathrm{x}$ & 2.3 & 1.3 & 6.3 & 22.6 & 4.3 \\
\hline & $\mathrm{y}$ & 21.8 & 11.6 & 26.6 & 13.1 & 12.8 \\
\hline \multirow[t]{2}{*}{$\mathrm{W} 3 \times 1.5-\mathrm{P} \times 1.0$} & $\mathrm{x}$ & 12.5 & 12.6 & 6.4 & 3.8 & 13.4 \\
\hline & y & 2.8 & 10.8 & 4.5 & 5.5 & 4.7 \\
\hline \multirow[t]{2}{*}{$\mathrm{W} 3 \times 1.5-\mathrm{P} \times 1.35$} & $\mathrm{x}$ & 14.2 & 14.3 & 8.5 & 7.0 & 15.4 \\
\hline & $\mathrm{y}$ & 5.3 & 13.8 & 6.6 & 7.9 & 7.2 \\
\hline \multirow[t]{2}{*}{$\mathrm{W} 4 \times 1.5-\mathrm{P} \times 1.0$} & $\mathrm{x}$ & 10.8 & 10.5 & 6.0 & 6.0 & 11.9 \\
\hline & $\mathrm{y}$ & 5.1 & 9.9 & 7.6 & 6.0 & 6.1 \\
\hline \multirow[t]{2}{*}{$\mathrm{W} 4 \times 1.5-\mathrm{P} \times 1.35$} & $\mathrm{x}$ & 12.4 & 12.0 & 6.1 & 8.8 & 13.7 \\
\hline & $\mathrm{y}$ & 7.2 & 13.0 & 9.2 & 8.3 & 8.7 \\
\hline \multirow[t]{2}{*}{$\mathrm{W} 6 \times 1.5-\mathrm{P} \times 1.0$} & $\mathrm{x}$ & 2.0 & 0.6 & 5.2 & 15.6 & 3.5 \\
\hline & $\mathrm{y}$ & 13.9 & 8.3 & 16.1 & 9.1 & 95 \\
\hline \multirow[t]{2}{*}{$\mathrm{W} 6 \times 1.5-\mathrm{P} \times 1.35$} & $\mathrm{x}$ & 4.2 & 3.0 & 7.4 & 17.2 & 59 \\
\hline & $\mathrm{y}$ & 15.2 & 11.5 & 17.0 & 11.1 & 12.2 \\
\hline
\end{tabular}

In wind case 4 and 6, only half of the anticlastic canopy is loaded under downward and upward acting wind pressure, respectively. Case 4 should thus be compared with case 3 and case 6 with case 1 . In case 4 the same distributed load is applied but only over half of the canopy compared to case 3 which results in a small reduction of $1.8 \mathrm{kN} / \mathrm{m}$ in the warp direction and an increase of $1.9 \mathrm{kN} / \mathrm{m}$ in weft direction in the membrane stress in the central point. It should be noticed that because of an overall small decrease in the distributed load and only half the surface that is loaded in case 6 versus case 1 , the difference in the central point is larger with an increase of $1.9 \mathrm{kN} / \mathrm{m}$ in the warp direction and a reduction of $6.6 \mathrm{kN} / \mathrm{m}$ in weft direction of the membrane stress in the central point. Cases 3, 4 and 6 are thus not dominating the design. However, because of the downward acting wind pressure, the highest stresses in $\mathrm{x}$-direction in point 2 occur in the mid-wall point. High stresses in $\mathrm{x}$-direction correspond with large deflections of the hanging cables which might indicate ponding. At no time, this 
potential phenomenon may occur as it would cause rupture of the membrane in case of snow or water accumulation. Therefore, the authors decided to verify ponding in ULS, even though deflections are associated with SLS. Figure 5 shows the membrane stress distribution and Fig. 6 shows the deflections in ULS for wind load case 3 and the partial factor for prestress $\gamma_{P}=1.35$. In spite of the limited margin, no ponding is observed. Also under non-symmetric loading conditions ponding does not occur. An additional check against stress inversion and thus loss of prestress showed no problems.

The membrane stress distribution shows the need for random fields in the reliability assessment of membrane structures instead of using scalar random variables. The variation of the stresses along the length and the directional dependency in the warp and weft direction clearly demonstrate that a single scalar to represent the variability of the parameters such as stiffness can't capture the real structural behaviour.

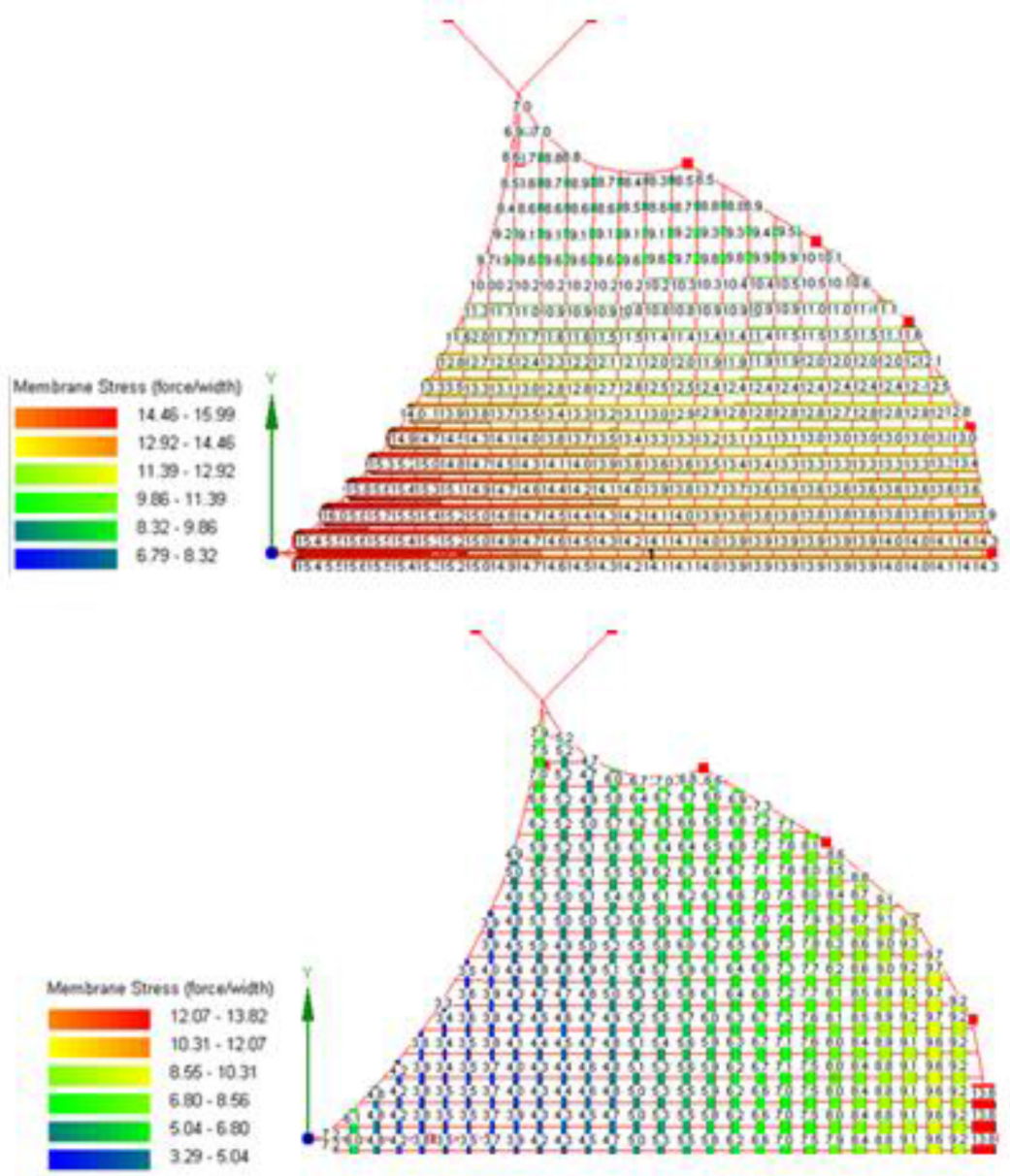

Figure 5: Membrane stress distribution in warp (top) and weft (bottom) direction for wind load case $3, \gamma_{Q}=1.5-\gamma_{P}=1.35$ (only half of the membrane is shown because of symmetry). 


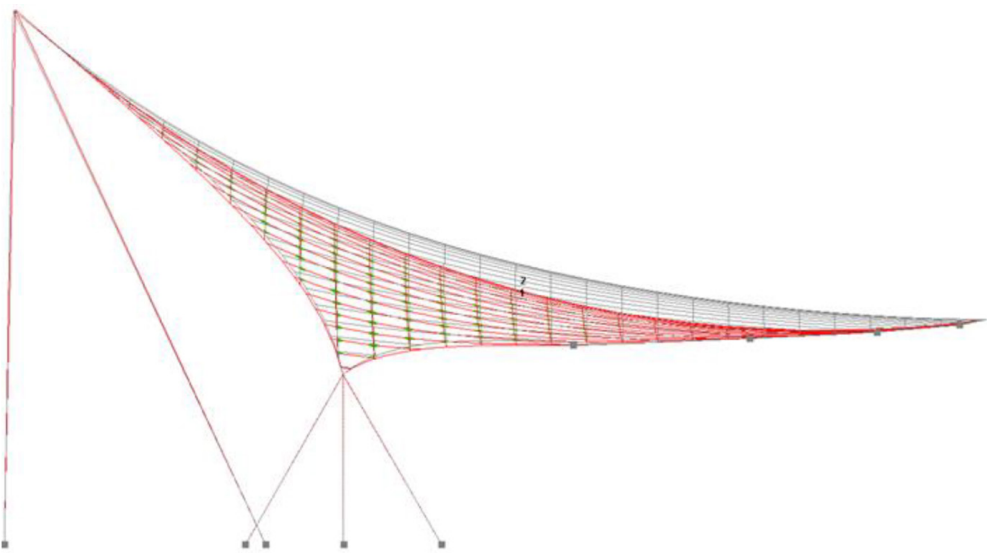

Figure 6: Ponding verification.

Table 4: Cable forces (tension) and mast and pole forces (compression) in [kN] without external loading (FF) and for the four design $\left(\gamma_{Q}=1.5\right)$ wind load cases $\mathrm{W} 1, \mathrm{~W} 3$, W4 and W6 (the un-factored values are given in Fig. 2).

\begin{tabular}{llllll}
\hline Load combinations & Edge cable & Lateral cable & Vertical cable & Mast & Poles \\
\hline PF-P $\times 1.0$ & 94 & 68 & 155 & 283 & 72 \\
FF-P $\times 1.35$ & $\mathbf{1 2 7}$ & $\mathbf{9 1}$ & $\mathbf{2 0 8}$ & $\mathbf{3 8 0}$ & $\mathbf{9 6}$ \\
$\mathrm{W} 1 \times 1.5-\mathrm{P} \times 1.0$ & 123 & 129 & 148 & 242 & 102 \\
$\mathrm{~W} 1 \times 1.5-\mathrm{P} \times 1.35$ & 149 & $\mathbf{1 4 6}$ & 199 & 330 & $\mathbf{1 2 0}$ \\
$\mathrm{W} 3 \times 1.5-\mathrm{P} \times 1.0$ & 127 & 67 & 201 & 361 & 68 \\
$\mathrm{~W} 3 \times 1.5-\mathrm{P} \times 1.35$ & $\mathbf{1 5 6}$ & 66 & $\mathbf{2 4 6}$ & $\mathbf{4 8 5}$ & 93 \\
$\mathrm{~W} 4 \times 1.5-\mathrm{P} \times 1.0$ & 116 & 65 & 180 & 336 & 72 \\
$\mathrm{~W} 4 \times 1.5-\mathrm{P} \times 1.35$ & 145 & 92 & 229 & 424 & 96 \\
$\mathrm{~W} 6 \times 1.5-\mathrm{P} \times 1.0$ & 105 & 100 & 147 & 256 & 92 \\
W6 $\times 1.5-\mathrm{P} \times 1.35$ & 134 & 114 & 199 & 349 & 113 \\
\hline
\end{tabular}

Table 4 summarizes the forces in the cables and the mast and poles. The support elements are first analysed without external (wind) loading (FF). It is clear that the partial factor for prestress $\gamma_{P}=1.35$ is applicable to the steel elements according to the Eurocodes for steel structures (values highlighted in bold). When introducing the wind load cases, the dominating forces (underlined values highlighted in bold) occur in the LC and poles for the upward acting wind pressure (wind load case 1) and are symmetric. The dominating forces in $\mathrm{EC}, \mathrm{VC}$ and mast occur for the downward acting wind pressure (wind load case 3). This is clearly in line with the expected structural behaviour under these load case assumptions. Furthermore, although a small difference in values for the LC and poles in the non-symmetrical load cases 4 and 6 could be observed, the effect is small because of a distribution of stresses in the membrane. 
Deflections for the four load cases in SLS (with the partial factor for wind and for prestress equal to 1.0) were calculated in EASY. Wind case 1 showed the highest maximum [7] deflection for upward wind acting pressure though not causing inversion or ponding. In SLS the partial factor for prestress is 1.0. Ponding has been checked in ULS, thus with higher loads, as well and did not cause problems. Note however that there a partial factor for prestress equal to 1.35 was taken which increases the stiffness. Further guidelines are needed on this in the Eurocodes.

\section{CONCLUSIONS}

In this study a pretensioned membrane structure was analysed according to the Eurocode, using a partial factor for prestress of 1.0 and 1.35 for the membrane in ULS.

The partial factor for prestress 1.35 in ULS has to be used for the dimensioning of the steel supporting structure. A partial factor for the membrane prestress higher than 1.0 takes into account that: (1) in practice the initial pretension of the membrane could be higher than the design value and (2) a decrease in tension in time due to the creep phenomenon could be anticipated without an excessive increase in weight of the structure.

A study of the stress distribution for other membrane structures is needed (different shapes, typologies, material properties ...) to be able to claim general conclusions. Further research will focus on the structural reliability of membrane structures. This article helps with a better understanding of the effect of the partial factors for prestress on the membrane stress distribution. A clear dependence of membrane stresses on the direction because of the orthotropic mechanical properties of the membrane, on the boundary conditions at the edges connecting the structural membrane with the supporting structure and on the location in the membrane (variability along the length/width) could be observed. This assessment shows the need for a sensitivity analysis to determine the parameters that need to be varied in a future probabilistic approach. Bearing in mind the goal of the research 'developing a semi-probabilistic design methodology for tensile structures according to the Eurocodes', the authors made a first step towards a reliability assessment for a simple example of a three cable segments cable net (work will be presented on the 14th edition of the International Probabilistic Workshop (IPW2016), which will take place from 5 to 7 December 2016 in Ghent, Belgium [9]). The ongoing research opens new perspectives in the reliability analysis of tensioned structures.

\section{ACKNOWLEDGEMENTS}

The authors want to thank prof. Em. W. P. De Wilde (Vrije Universiteit Brussel), Prof. R. Caspeele (UGent) and the members of Working Group 5 'From material to structure and limit states: codes and standardisation' of Cost Action TU1303 'Novel Structural skins' for inspiring discussions and feedback on the topic.

\section{REFERENCES}

[1] Gulvanessian, H., Calgaro, J.A. \& Holicky, M., Designers' Guide to the Eurocode: Basis of Structural Design EN 1990, 2nd edn, ICE, p. 190, 2012. http://dx.doi.org/10.1680/bsd.41714

[2] Mollaert, M., Devos, R., Pyl, L. \& De Laet, L., The design of tensile surface structures - From a hand calculation in 1958 to a contemporary numerical simulation. Steel Construction - Design Research, 8(4), pp. 251-258, 2015.

[3] NEN-EN1990, Eurocode: Grondslagen van het constructief ontwerp, pp. 1-92, 2002.

[4] Stranghöner, N., Uhlemann, J.,Bilginoglu, F., Bletzinger, K.U., Bögner-Balz, H., Corne, E., Gibson, N., Gosling, P., Houtman, R., Llorens, J., Malinowsky, M., Marion, J.M., Mollaert, M., Nieger, M., Novati, G., Sahnoune, F., Siemens, P., Stimpfle, B., Tanev, V. 
\& Thomas, J.C., Scientific and Policy Report ( SaP-Report ). Background for European Structural Design of Tensile Membrane Structures.eds Joint Research Centre.

[5] EN1991-1-4., Eurocode 1 - Actions on structures - Part 1-4: General actions - Wind actions, pp. 9-92, 2005.

[6] Rika, D. \& Mollaert, M., A quest for early tensile structures on expo 58, 2015.

[7] Pyl, L., Wang, X., De Smedt, Colliers, J., Mollaert, M \& De Laet, L., Existing Eurocodes applied to a membrane structure. International Symposium Novel Structural Skins - Improving Sustainability and Efficiency through new Structural Textile Materials Designs, Accepted for publication, 2016.

[8] Technet GmbH, "Easy. [Online], 2010, available at: http://www.technet-gmbh.com/ index.php?id=63\&L=1."

[9] Mollaert, M., Pyl, L., De Smedt, E. \& Caspeele, R., Structural reliability in design and analysis of tensile structures. In Proceedings of the 14th International Probabilistic Workshop, Ghent, Belgium, Accepted for publication, 2016.

[10] State Archive (Brussels), Fund Expo 58; File: 2321-2326, 2394-2399. 